\title{
Fatty acid extract from CLA-enriched egg yolks can mediate transcriptome reprogramming of MCF-7 cancer cells to prevent their growth and proliferation
}

Aneta A. Koronowicz ${ }^{1 *}$, Paula Banks ${ }^{1}$, Dominik Domagała ${ }^{1}$, Adam Master ${ }^{2}$, Teresa Leszczyńska', Ewelina Piasna ${ }^{1}$, Mariola Marynowska ${ }^{1}$ and Piotr Laidler ${ }^{3}$

\begin{abstract}
Background: Our previous study showed that fatty acids extract obtained from CLA-enriched egg yolks (EFA-CLA) suppressed the viability of MCF-7 cancer cell line more effectively than extract from non-enriched egg yolks (EFA). In this study, we analysed the effect of EFA-CLA and EFA on transcriptome profile of MCF-7 cells by applying the whole Human Genome Microarray technology.

Results: We found that EFA-CLA and EFA treated cells differentially regulated genes involved in cancer development and progression. EFA-CLA, compared to EFA, positively increased the mRNA expression of TSC2 and PTEN tumor suppressors as well as decreased the expression of NOTCH1, AGPS, GNA12, STAT3, UCP2, HIGD2A, HIF1A, PPKAR1A oncogenes.

Conclusions: We show for the first time that EFA-CLA can regulate genes engaged in AKT/mTOR pathway and inhibiting cell cycle progression. The observed results are most likely achieved by the combined effect of both: incorporated CLA isomers and other fatty acids in eggs organically modified through hens' diet. Our results suggest that CLA-enriched eggs could be easily available food products with a potential of a cancer chemopreventive agent.
\end{abstract}

Keywords: AKT/mTOR pathway, CLA-enriched egg yolks, DNA microarray, Cancer chemoprevention, MCF-7 cancer cells, Transcriptome, SFA/MUFA

\section{Introduction}

Conjugated linoleic acid (CLA) term includes several isomers of linoleic acid (18:2), naturally present in ruminant and dairy products, due to the activity of the rumen microflora [25, 30]. In numerous studies, CLA was shown to have several beneficial properties on human health. Researchers examined its effect on stimulating the immune system [1], reducing cancerogenesis [32, 52], atherogenesis [34], diabetes, and obesity [54]. However, most of the available literature was focused on the activity of isolated, pure substances. In addition,

\footnotetext{
*Correspondence: aneta.koronowicz@gmail.com

${ }^{1}$ Department of Human Nutrition, Faculty of Food Technology, University of Agriculture, Krakow, Poland

Full list of author information is available at the end of the article
}

according to available data, the consumable quantities of naturally occurring CLA are relatively too low to effectively impact human health [27]. The recommended effective dose of CLA was estimated at least 1.5-3.5 g/day [13], while natural ruminant products contain between 1.2 and $12.5 \mathrm{mg}$ per gram of fat $[25,30,47,78]$ and in poultry CLA concentration remains relatively low, at 0.6 to $0.9 \mathrm{mg}$ per gram of fat [13]. Enhancing CLA concentration in food products such as eggs, chosen dairy products/yogurts, and meat could then become an alternative to synthetic CLA supplements. Indeed, studies have shown an easy incorporation of CLA into eggs of chickens by diet fortification $[11,65,74]$ and that CLA-enriched eggs meet the requirements of functional food [24]. 
Little is known about the effect of fatty acids (FA) from CLA-enriched food products on cancer cells $[16,46]$. Our previous study showed that FA extracts obtained from CLA-enriched egg yolks (EFA-CLA) suppressed the viability of MCF-7 cancer cell line more effectively than the extracts from non-enriched egg yolks (EFA) [32]. To analyze the potential molecular mechanism, we decided to compare the effects of both extracts on MCF-7 cells transcriptome profile.

The whole-genome DNA microarray technology has become a very powerful tool to analyze global gene expression profiles, and in multiple studies, it has been shown to be an effective method for detecting genomic variation of closely related samples. Finally, we identified and analyzed differently expressed genes based on family, molecular functions, biological processes, cellular components, or pathways. As suggested in this article, relationships between studied genes require a confirmation at protein level; nevertheless, the microarray results are a valuable and multi-faceted source of information for other scientists and a foundation for further in vivo research [67].

\section{Methods}

\section{Hens' and eggs' management}

The Animal Ethics Committee of the National Institute of Animal Production (Poland) approved all experiments involving animals (approval number: 851/2011). All applicable international, national, and/or institutional guidelines for the care and use of animals were followed.

Forty-eight Isa Brown laying hens (26 weeks old) were housed in a controlled room under 14/10 h light/dark cycle, given free access to water and commercial starter diet ('DJ' feed). After a 1-week adaptation period, an equal number of hens was randomly allocated to the control or experimental group for 4 months of the experiment. Diets (Additional file 1: Table S1) were calculated to provide $2700 \mathrm{kcal} / \mathrm{kg}$ and $17 \%$ crude protein. The $0.75 \%$ dietary CLA (TONALIN FFA 80, BASF Company, Germany) concentration was based on previously determined formula [24] and contained $80 \%$ CLA in 50:50 ratio for cis-9,trans-11 and trans-10,cis12 isomers. Eggs were collected daily for the period of 10 weeks and stored at $4{ }^{\circ} \mathrm{C}$. Yolks were separated from albumen, homogenized with rotary homogenizer, and frozen at $-20{ }^{\circ} \mathrm{C}$. Samples were then lyophilized (Martin Christ Model Alpha 1-4, Germany) and again stored at $-20{ }^{\circ} \mathrm{C}$. The total dry matter was determined by oven drying method [3] and the total fat content was determined by Soxhlet method (Soxtec Avanti's 2050 Auto Extraction Unit, Tecator Foss, Sweden) using petroleum ether as a solvent [23].

Fatty acids extraction and GC/MS analysis Lipids from control and CLA-enriched yolks were extracted by using modified Folch method [22]. One gram per liter of butylated hydroxytoluen (BHT) was used as an antioxidant. Briefly, after overnight incubation with chloroform/methanol (2:1) solution, samples were filtrated and mixed with $4 \mathrm{~mL}$ of $0.88 \%$ sodium chloride solution to obtain phase separation. Chloroform lipids layer was then carefully dried under nitrogen. Ten milligrams of each lipid extract was subjected to saponification (20 min, $60{ }^{\circ} \mathrm{C}$ ) with $0.5 \mathrm{M} \mathrm{KOH} /$ methanol followed by methylation with $14 \%(v / v) \mathrm{BF} 3 /$ methanol $\left(15 \mathrm{~min}, 60^{\circ} \mathrm{C}\right)$ and extraction with hexane. The obtained fatty acid methyl esters (FAME) were analyzed by GC/MS (Additional file 2: Table S2). The profile of EFA-CLA and EFA was expressed as percentage (\%) of relative area, obtained by area normalization (FA peak area relative to chromatogram total area). For the treatment, lipid extracts were subjected to the basic hydrolysis $\left(0.5 \mathrm{M} \mathrm{KOH}, 60{ }^{\circ} \mathrm{C}\right.$, $15 \mathrm{~min}$ ) and extracted with hexane. The free fatty acids were then dissolved in ethanol at the stock concentration $1 \mathrm{~g} / \mathrm{mL}$ and stored under nitrogen in the temperature of $-20{ }^{\circ} \mathrm{C}$.

\section{Cell culture and treatment}

Human breast adenocarcinoma cell line MCF-7 (ATCC $\mathrm{HTB}_{2} 2^{\mathrm{TM}}$ ) was purchased from the American Type Culture Collection. Cells were cultured according to the manufacturer's procedure. Cells were seeded in culture plates (BD Biosciences) for $24 \mathrm{~h}$. After that time, growing medium was replaced by a medium containing (a) fatty acid extract from CLA-enriched egg yolks (EFACLA) and (b) fatty acids extract from non-enriched egg yolks (EFA), both at the concentration of $0.5 \mathrm{mg} / \mathrm{mL}$. We used (c) cell cultures only in growth medium (empty control (EC)) and (d) cell cultures treated with only a solvent of fatty acids (ET-ethanol) at final concentration $0.1 \%$, as a negative control (NC).

\section{Cell proliferation}

Cell proliferation was determined with 5 ' -bromo- 2 '-deoxy-uridine (BrdU) Labeling and Detection Kit III (Roche), according to manufacturer's instruction.

\section{Microarray analysis of gene expression profile}

Whole Human Genome Microarrays containing about 50000 probes (Agilent Technologies, USA) were used to establish the expression profile of each tested sample. Total RNA was isolated from cells using RNA isolation kit (A\&A Biotechnology, Poland). RNA quantity was measured with NanoDrop (NanoDrop Technologies, USA). The analysis of its quality and integrity was performed with BioAnalyzer (Agilent, USA). Only samples with RNA integrity number (RIN) $\geq 8.0$ were included in the analysis which was performed using SurePrint G3 Human Gene Expression 8x60K v2 Microarray. Each slide contained eight microarrays representing about 50 
000 probe sets. The Low Input Quick Amp Labeling Kit, two-color (Agilent, USA) was used to amplify and label target RNA to generate complementary RNA (cRNA) for oligo microarrays used in gene expression profiling. The experiment was performed using a common reference design, where the common reference was a pool of equal amounts of RNA from control cells. On each of two-color microarrays, 300 ng of cRNA from the pool (labeled Cy3) and $300 \mathrm{ng}$ of cRNA (labeled Cy5) were hybridized. In total, 12 microarrays were run-three for each experimental group. Microarray hybridization was performed with the Gene Expression Hybridization Kit (Agilent Technologies, USA), according to the manufacturer's protocols. RNA Spike In Kit (Agilent Technologies, USA) was used as an internal control. Acquisition and analysis of hybridization intensities were performed using the Agilent DNA microarray scanner. Data were extracted and background was subtracted using standard procedures contained in the Agilent Feature Extraction (FE) Software version 10.7.3.1. FE performs Lowess normalization. Samples underwent quality control and the results showed that each sample had a similar QC metric profile. The next step was filtering probe sets by flags to remove poor quality probes (absent flags). Microarray data were deposited at the Gene Expression Omnibus data repository under the number GSE65397 and followed MIAME requirements. To identify signaling pathways and gene functions, the microarray data were analyzed using Panther Classification System-an online database.

\section{RT and real-time PCR analysis}

Reverse transcription was performed using $1 \mu \mathrm{g}$ of total RNA isolated from the cells by using the Maxima first Strand cDNA Synthesis kit for RT-qPCR (Thermo Scientific). A quantitative verification of genes was performed using the CFX96 Touch $^{\text {тм }}$ Real-Time PCR Detection System instrument (Bio-Rad), utilizing the SYBR Green Precision Melt Supermix kit (Bio-Rad). Conditions of individual PCR reactions were optimized for given pair of oligonucleotide primers (Additional file 3: Table S3). Basic conditions were as follows: $95{ }^{\circ} \mathrm{C}$ for $10 \mathrm{~min}, 45 \mathrm{PCR}$ cycles at $95^{\circ} \mathrm{C}, 15 \mathrm{~s} ; 59^{\circ} \mathrm{C}, 15 \mathrm{~s} ; 72^{\circ} \mathrm{C}$, $15 \mathrm{~s}$, followed by melting curve analysis $\left(65-97^{\circ} \mathrm{C}\right.$ with $0.11{ }^{\circ} \mathrm{C}$ ramp rate and five acquisitions per $1{ }^{\circ} \mathrm{C}$ ). Results were normalized using at least two reference genes (GAPDH, HPRT1, ACTB, or HSP90AB1) and were calculated using the $2^{-\Delta \Delta C} \mathrm{~T}$ method [39].

\section{Statistical analysis}

Each treatment included three replicates and the experiment was repeated three times. Statistical analysis for microarrays was performed using Gene Spring 12.6.1 software (Agilent, USA). Statistical significance of the differences was evaluated using a one-way ANOVA and Tukey's HSD Post hoc test $(p<0.05)$. A multiple testing correction was performed using Benjamini and Hochberg false discovery rate (FDR) $<5 \%$. Other experiments were assessed by Student's $t$ tests.

\section{Results \\ Bird performance and egg composition}

There were no significant differences in egg production between hens as well as egg characteristics [33]. Fatty acid profile in CLA-enriched egg yolks was significantly affected by dietary CLA fortification (Fig. 1). Both CLA isomers were found incorporated into the yolk, and their concentration did not reflect their initial proportion in the experimental diets (Additional file 1: Table S1), with the preference for the cis-9,trans-11 isomer. Compared to the control, feeding with $0.75 \%$ of dietary CLA significantly increased $(p<0.001)$ total SFA concentration at the expenses of MUFA $(p<0.001)$ (Fig. 1 and [33]).

\section{Cell proliferation}

EFA-CLA extract at a concentration of $0.5 \mathrm{mg} / \mathrm{mL}$ suppressed MCF-7 cell proliferation more effectively than the extract from non-enriched egg yolks. Specifically, treatment with EFA-CLA reduced the cell proliferation by approximately $40 \%$ compared to the negative control, while EFA reached 20 \% (Fig. 2). Moreover, this effect was weaker for estrogen-negative MDA-MB-231 (Additional file 4: Figure S12) and not observed for a non-tumorigenic MCF-10A cell line (Fig. 3).

\section{Effect of applied treatments on MCF-7 cell line transcrip- tome profile}

The analysis was performed on 1589 transcripts, of which 160 were differently expressed between EFA-CLA and EFA studied groups (Fig. 4 and Additional file 5: Table S4). We omitted 21 genes, which could have been directly affected by the solvent (ET) leaving 139 genes (Additional file 6: Table S10). Further analysis showed 69 transcripts shared by all three comparison groups: EFA-CLA vs. EFA, NC vs. EFA-CLA, and NC vs. EFA and 36 transcripts shared by EFA-CLA vs. EFA and NC vs. EFA. We determined 34 transcripts unique only to EFA-CLA vs. EFA. Among those, 11 were uncharacterized in available databases. Finally, we identified 18 (underlined) that, according to the available data, can be linked to cancer development and/or progression and which are involved in important cellular processes including regulation of cell cycle, apoptosis, or cell metabolism (Table 1). For those, the differences in expression between EFA and $\mathrm{NC}$ were statistically insignificant (Additional file 7: Table S5). 


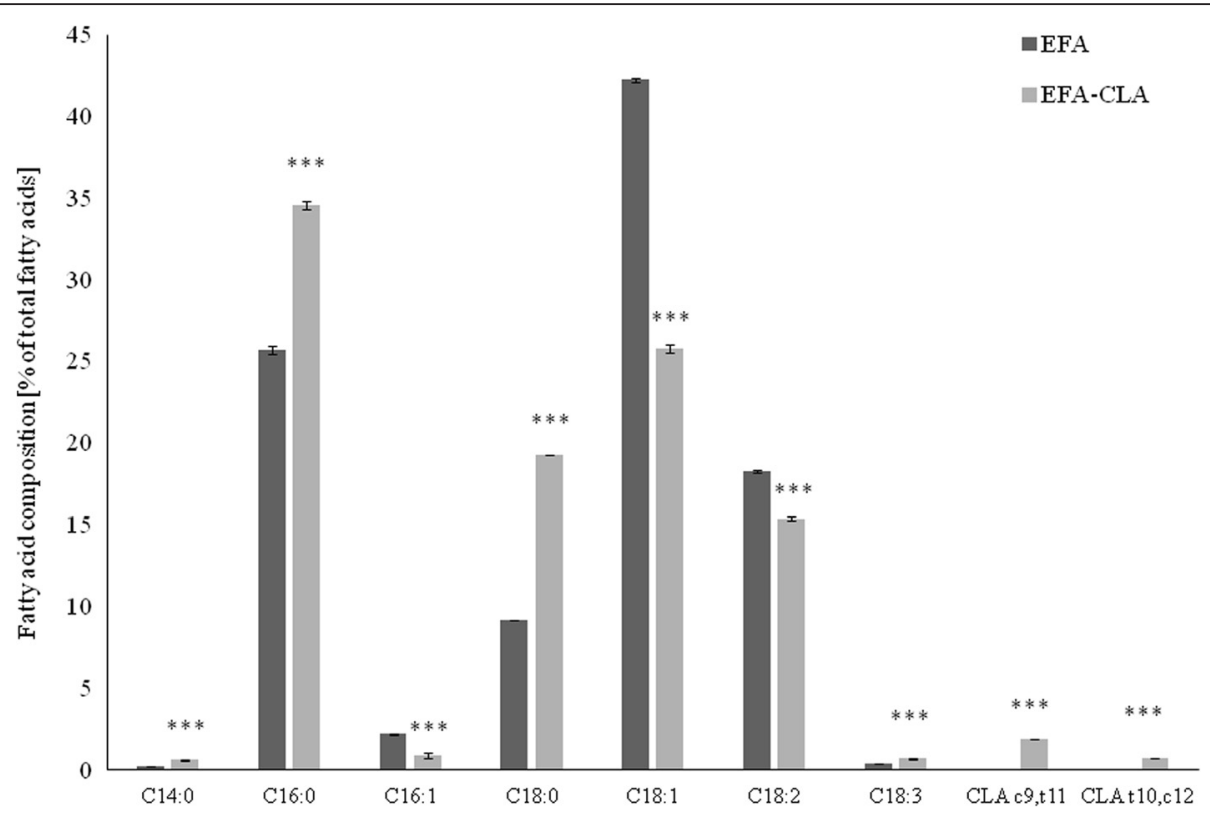

Fig. 1 Effect of dietary CLA on relative (\%) fatty acids composition of egg yolks. Statistical significance of treatment: ${ }^{*} p<0.05$; ${ }^{* *} p<0.01 ;{ }^{* *} p<0.001$

\section{Real-time PCR}

To validate microarray data, we selected eight random genes from EFA-CLA vs. EFA comparison group: NOTCH1, HIGD2A, PPKAR1A, UPC2, NAP1L1, CAM$S A P 2, P P P 2 R 5 E$, and TSC2 $(p<0.05$, Table 2$)$. Our analysis showed a significant decrease in the messenger RNA (mRNA) expression of NOTCH1, HIGD2A, $P P K A R 1 A$, and $U C P 2$ and an increase in the expression of CAMSAP2, PPP2R5E, and TSC2 genes due to the EFA-CLA treatment. Interestingly, only RT-qPCR results for NAP1L1 exhibited changes in the opposite direction than the microarray.

\section{GO molecular complete analysis}

Next, we examined the Gene Ontology (GO) for EFACLA vs. EFA differently regulated genes, using Panther Classification System. Results obtained from analysis of the signaling pathways, biological processes, molecular functions, and protein classes are presented in supplementary material (Additional file 8: Table S6, Additional file 9:

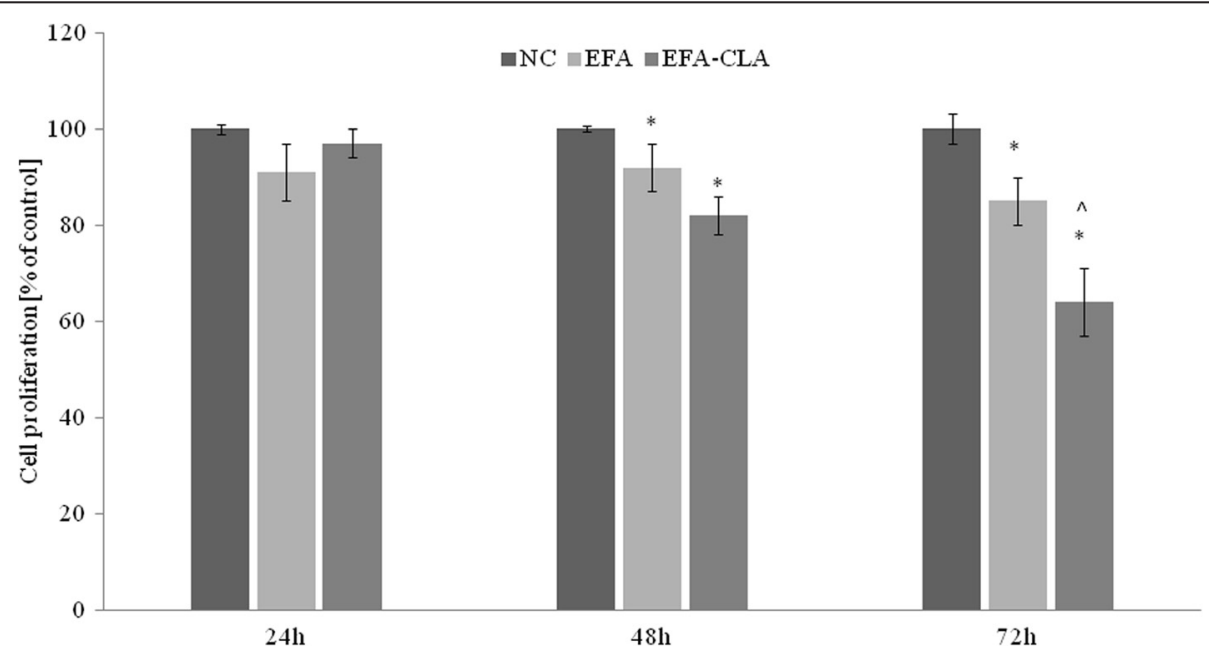

Fig. 2 Effect of EFA-CLA on MCF-7 cells proliferation. Values are expressed as means \pm SEM for the N $\geq 9$, standarized to NC as $100 \%$. Statistical significance was based on Student's $t$ test ${ }^{*} p<0.05$ vs. NC and $\wedge p<0.05$ vs. EFA 


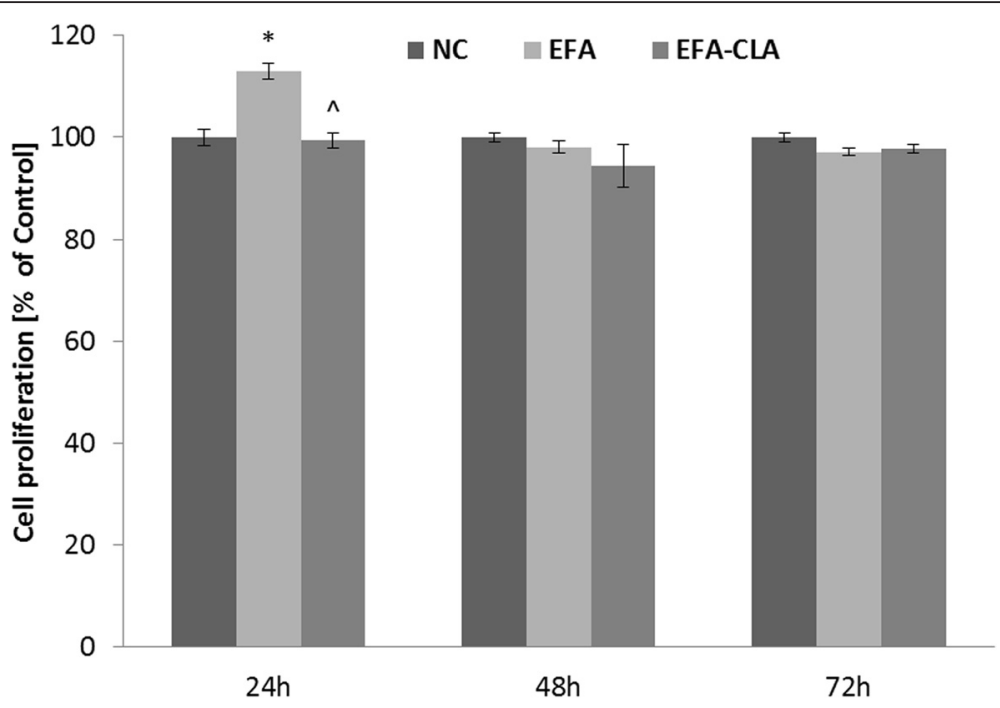

Fig. 3 Effect of EFA-CLA on MCF-10A cells proliferation. Values are expressed as means \pm SEM for the $N \geq 9$, standarized to NC as $100 \%$. Statistical significance was based on Student's $t$ test ${ }^{*} p<0.05$ vs. NC and $\wedge p<0.05$ vs. EFA

Table S7, Additional file 10: Table S8, and Additional file 11: Table S9).

\section{Effect of EFA-CLA on oncogenic pathways}

In addition to signaling pathways listed in Additional file 8: Table S6, we aimed to study the connections between all the transcripts from Table 1, especially in terms of oncogenic pathways (Fig. 5) [79]. Our results showed that EFA-CLA treatment affected the downstream genes of the mammalian target of rapamycin (mTOR) signaling pathway. The increased mRNA expression of PTEN, PPP2R5E, and TSC2 and decreased expression of GNA12, UPC2,
AGPS, ANAX5A, and HIF1A, together with observed reduced proliferation of $\mathrm{MCF}-7$, suggest that EFA-CLA negatively regulates AKT/mTOR pathway.

\section{Discussion}

Breast cancer is one of the most common malignancies among women [21]; however, despite extensive research, the cellular processes that lead to carcinogenesis have not yet been fully explained. In the current research, we chose the estrogen receptorpositive $(\mathrm{ER}+)$ MCF-7 breast cancer cell line-the most studied cellular model of breast cancer $[26,59,73]$.

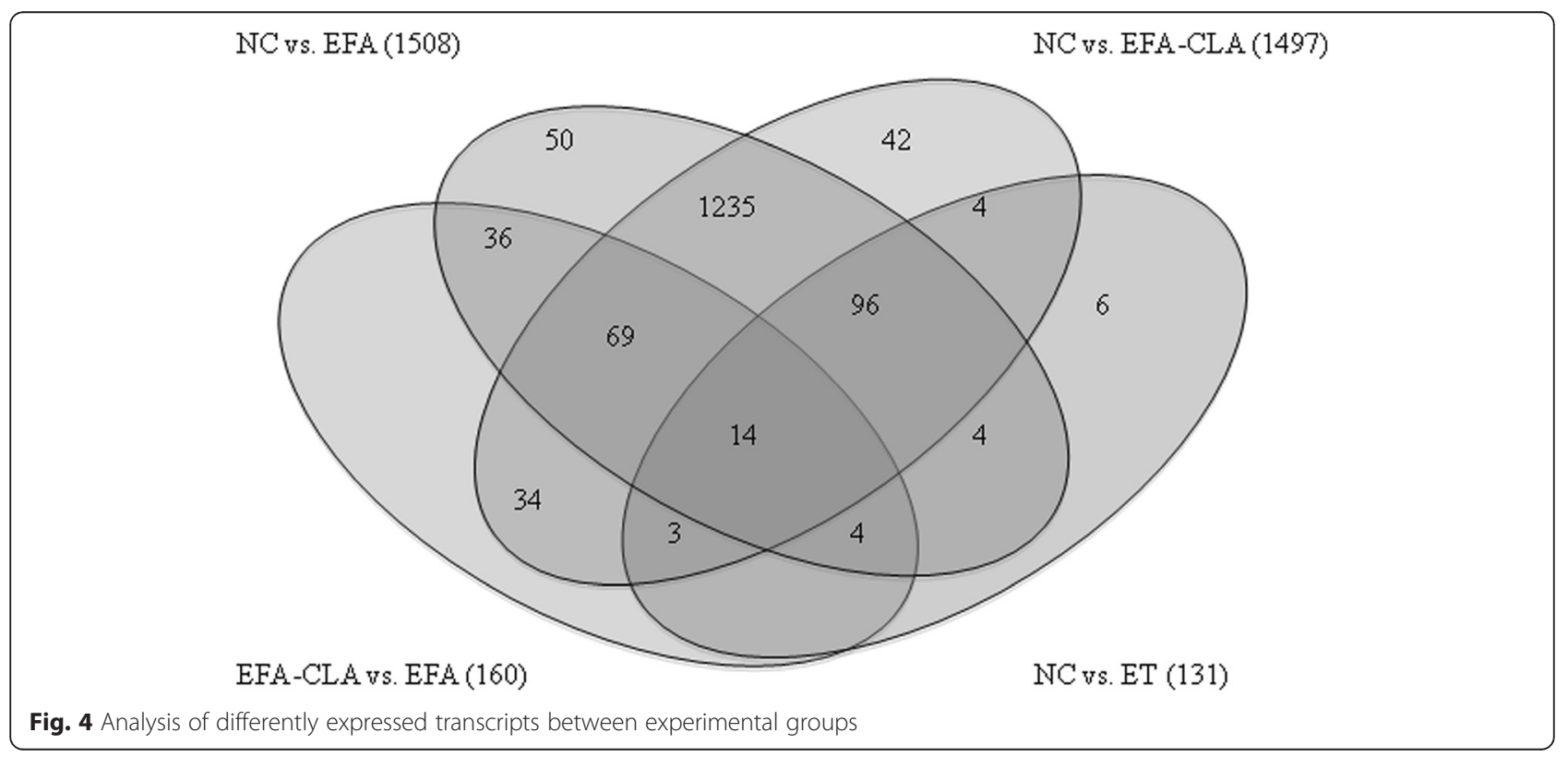


Table 1 The list of the differently regulated EFA-CLA vs. EFA specific transcripts in MCF-7 cell line

\begin{tabular}{|c|c|c|c|}
\hline Gene Symbol & Adjusted $p$ values & FC value & Gene name \\
\hline NOTCH1 & 0.0146 & -2.63 & Notch homolog 1, translocation-associated \\
\hline AGPS & 0.0424 & -2.19 & Alkylglycerone phosphate synthase \\
\hline GNA12 & 0.0009 & -1.56 & Guanine nucleotide binding protein (G protein) alpha 12 \\
\hline HIF1A & 0.0184 & -1.56 & $\begin{array}{l}\text { Hypoxia inducible factor 1, alpha subunit (basic helix-loop-helix } \\
\text { transcription factor) }\end{array}$ \\
\hline STAT3 & 0.0088 & -1.32 & $\begin{array}{l}\text { Signal transducer and activator of transcription } 3 \\
\text { (acute-phase response factor) }\end{array}$ \\
\hline UCP2 & 0.0083 & -1.29 & Uncoupling protein 2 (mitochondrial, proton carrier) \\
\hline HIGD2A & 0.0089 & -1.27 & HIG1 hypoxia inducible domain family, member $2 \mathrm{~A}$ \\
\hline WASH1 & 0.0038 & -1.27 & WAS protein family homolog 1 \\
\hline BIN3 & 0.0477 & -1.16 & Bridging integrator 3 \\
\hline PRKAR1A & 0.0462 & -1.14 & Protein kinase, cAMP-dependent, regulatory, type I, alpha \\
\hline NDUFB11 & 0.0105 & -1.13 & $\begin{array}{l}\text { NADH dehydrogenase (ubiquinone) } 1 \text { beta subcomplex, } \\
11,17.3 \mathrm{kDa}\end{array}$ \\
\hline ANXA5 & 0.0311 & -1.05 & Annexin A5 \\
\hline SMS & 0.0399 & 1.08 & Spermine synthase \\
\hline PPP2R5E & 0.0009 & 1.13 & Protein phosphatase 2 , regulatory subunit B', epsilon isoform \\
\hline NAP1L1 & 0.0335 & 1.14 & Nucleosome assembly protein 1-like 1 \\
\hline PTEN & 0.0382 & 1.15 & $\begin{array}{l}\text { Phosphatidylinositol 3,4,5-trisphosphate 3-phosphatase and } \\
\text { dual-specificity protein phosphatase PTEN }\end{array}$ \\
\hline LOC646214 & 0.0213 & 1.16 & p21 protein (Cdc42/Rac)-activated kinase 2 pseudogene \\
\hline LMCD1 & 0.0067 & 1.21 & LIM and cysteine-rich domains 1 \\
\hline CAMSAP2 & 0.0174 & 1.23 & Calmodulin regulated spectrin-associated protein family, member 2 \\
\hline TSC2 & 0.0177 & 1.26 & Tuberous sclerosis 2 \\
\hline FL 45139 & 0.0406 & 1.33 & Fし45139 protein \\
\hline $\mathrm{CHSY}_{3}$ & 0.0399 & 1.72 & Chondroitin sulfate synthase 3 \\
\hline OVOS & 0.0403 & 1.72 & Ovostatin \\
\hline$S C D$ & 0.19 & $-1.18^{\mathrm{NS}}$ & Stearoyl-CoA desaturase (delta-9-desaturase) \\
\hline
\end{tabular}

Statistical significance of treatment: $p<0.05$; NS $p>0.05$; bolded genes are to be associated with cancer

Table 2 The validation of microarray results with RT-qPCR in MCF-7 cell line (EFA-CLA vs. EFA)

\begin{tabular}{|c|c|c|c|c|}
\hline $\begin{array}{l}\text { Gene } \\
\text { symbol }\end{array}$ & $\begin{array}{l}\text { Adjusted } \\
p \text { values }\end{array}$ & $\begin{array}{l}\text { FC value } \\
\text { RT-qPCR }\end{array}$ & $\begin{array}{l}\text { FC value } \\
\text { Microarray }\end{array}$ & Gene name \\
\hline NOTCH1 & 0.0022 & -2.02 & -2.63 & Notch homolog 1, translocation-associated \\
\hline$H I G D 2 A$ & 0.0121 & -1.75 & -1.27 & $\begin{array}{l}\text { HIG1 hypoxia inducible domain family, } \\
\text { member } 2 \mathrm{~A}\end{array}$ \\
\hline PRKAR1A & 0.0047 & -1.58 & -1.14 & $\begin{array}{l}\text { Protein kinase, cAMP-dependent, regulatory, } \\
\text { type I, alpha }\end{array}$ \\
\hline UCP2 & 0.0023 & -1.53 & -1.29 & $\begin{array}{l}\text { Uncoupling protein } 2 \text { (mitochondrial, proton } \\
\text { carrier) }\end{array}$ \\
\hline NAP1L1 & 0.0023 & -1.37 & 1.17 & Nucleosome assembly protein 1-like 1 \\
\hline CAMSAP2 & 0.0031 & 1.57 & 1.23 & $\begin{array}{l}\text { Calmodulin regulated spectrin-associated } \\
\text { protein family, member } 2\end{array}$ \\
\hline PPP2R5E & 0.0035 & 1.72 & 1.13 & $\begin{array}{l}\text { Protein phosphatase } 2 \text {, regulatory subunit } B^{\prime} \text {, } \\
\text { epsilon isoform }\end{array}$ \\
\hline TSC2 & 0.0001 & 1.85 & 1.26 & Tuberous sclerosis 2 \\
\hline
\end{tabular}




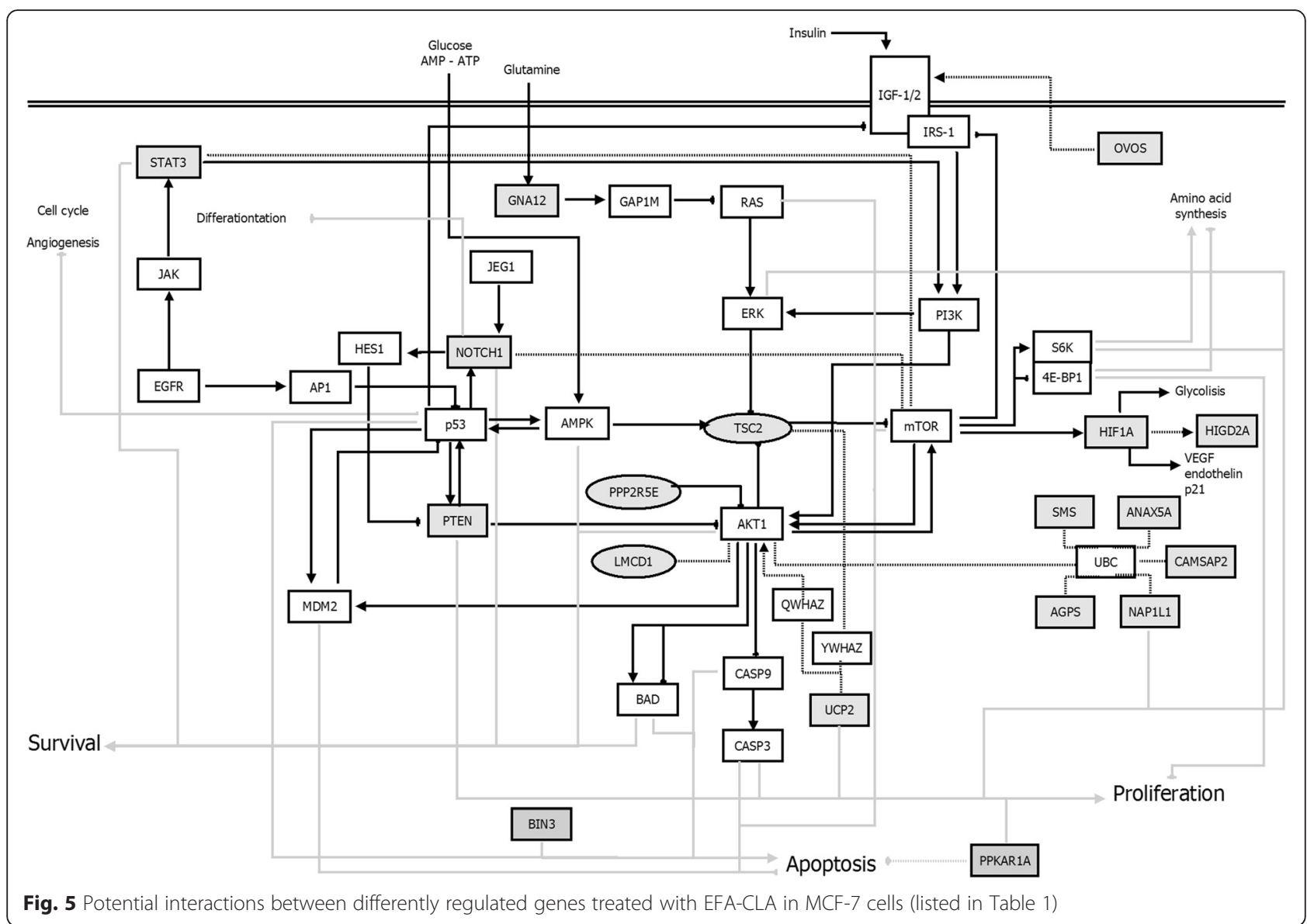

One of the main reasons behind our choice is that the $(\mathrm{ER}+)$ breast cancers are the most frequently diagnosed breast cancer subtype.

CLA is an extensively studied compound, and research findings showed a variety of possible beneficial effects of dietary CLA on human health. In addition, some of the molecular aspects of CLA mechanisms of action have been already described, and to our knowledge, Murphy et al. [50] applied microarray technique to show the effects of CLA isomers on the global gene expression using Caco-2 cells. However, most of published results are based on studying pure, isolated isomers which may not reflect the effect of a food product naturally enriched in CLA. Thus, our research would be the first to address the effects of the extract from CLA-enriched egg yolks on a breast cancer cell model in a wide spectrum of the whole human genome.

Our previous experiments showed that EFA-CLA extract suppressed the viability of MCF-7 breast cancer cell line more effectively than extract from non-enriched egg yolks [32]. Our current study supports those findings not only for estrogen receptor-positive MCF- 7 but also for estrogen receptor-negative MDA-MB-231; however, the EFA-CLA effect was most notable for MCF-7 (Fig. 2 and Additional file 4: Figure S12), which we proposed to be associated with affected mTOR signaling pathway [8]. In addition, we also performed experiments on commercially available and described as a non-tumorigenic MCF-10A cell line (ATCC). Interestingly, we did not observe a decreased proliferation in that cell line after treatment with tested fatty acids (Fig. 3). Some authors recommend caution when using MCF-10A cell line as non-transformed human breast epithelial cells in carcinogenesis research. They point out their potential for morphological and phenotypic transformation [56]. However, it should be noted that, to some extent, this could be due to the modification of the cell line microenvironment, including culture conditions, presence of serum, and used medium [53, 76].

In the present manuscript, we discuss selected genes, which expression differs the most between cells treated with FA from CLA-enriched and non-enriched egg yolks (Table 1), specifically, in terms of their potential significance in the neoplastic process. Based on a scheme of the interactions between those genes (Fig. 5), we pointed the anti-proliferative and pro-apoptotic properties of EFA-CLA, specifically through the regulation of AKT/ mTOR signaling pathway. mTOR interacts with several 
proteins and forms two distinct complexes named mTOR complex 1 (mTORC1) and 2 (mTORC2) of which mTORC1 is currently better characterized. mTOR is a central controller of protein synthesis, cell growth, cell proliferation, and cell viability [37]. Several components of the PI3K/PTEN/AKT/mTOR pathway (Fig. 5) are frequently mutated in human cancers.

Most notably, our results showed that treatment of MCF-7 cells with EFA-CLA (compared to EFA) increased the mRNA expression of known tumor suppressors, such as TSC2, PTEN, PPP2R5E, and LMCD1. TSC2 complex is a key upstream regulator of $\mathrm{mTORC} 1$, and it constitutes of two proteins, TSC1 and TSC2, that interacts with each other. Mutations in either of them result in the development of the tuberous sclerosis complex (TSC), characterized by the growth of benign tumors in multiple vital organs [29]. Reduced expression of TSC2 was determined in the invasive breast cancer compared to normal mammary epithelium [45]. Another mTOR pathway inhibitor, PTEN, was also found up-regulated. PTEN is a p53-regulated tumor suppressor, which transcription can be enhanced by p53 protein-acting as a transcription factor. Although our microarrays did not show statistically significant change in TP53 mRNA expression in the EFA-CLA cells vs. EFA group, additional Western blot analysis clearly showed an accumulation of p53 at the protein levels in the EFA-CLA treated cells (data not shown). PTEN is one of the most frequently mutated genes in various human cancers $[9,17,70]$, including breast cancers, and is linked to aggressive tumors [64]. Information on PPP2R5E is limited, but it has been suggested as a potential negative regulator of PI3K/ AKT signaling (2016). It has been also found to act as a tumor suppressor in breast cancer [19] and gastric cancer cells [38].

During our analysis, we have also found other genes potentially associated with $\mathrm{PI} 3 \mathrm{~K} / \mathrm{AKT} / \mathrm{mTOR}$ pathway, which were down-regulated in cells: AGPS, ANXA5, STAT3, NOTCH1, PRKAR1A, and HIF1A (Table 1), after the treatment with EFA-CLA. Whether observed decrease in gene expression is the cause or the result of inhibition of $\mathrm{AKT} / \mathrm{mTOR}$ pathway requires further study. Zhu et al. [77] showed that phosphorylation of AKT1 in glioma and hepatic carcinoma cell lines was reduced simultaneously with AGPS silencing, whereas Benjamin et al. [6] showed that silencing of AGPS in breast cancer (including MCF-7) and melanoma cells manifested in a life-time reduction of cancer cells viability, tumor growth, and invasiveness. Although we did not find a direct link between ANXA5 and AKT/mTOR pathway (Fig. 5), its up-regulation may be a predictive factor for tumor stage and clinical outcome of colorectal cancer [71]. ANXA5 has been also found in a group of proapoptotic genes [48]. These data may suggest that the expression of ANXA5 could be dependent on the expression profile of other superior genes being a part of anti-tumor response of cells. In our study, we show a significant down-regulation of STAT3 and NOTCH1 gene under the influence of EFA-CLA. Phosphorylated STAT3 is being observed in nearly $70 \%$ of human cancers. Acting as an oncoprotein, it is constitutively activated in many primary human tumors, being activated by a number of different cytokines as well as oncoproteins, i.e., Src and Ras. NOTCH1 is associated with PI3K and PI3K-dependent activation of AKT1. It has been shown to play a role in growth, proliferation, and inhibition of apoptosis $[10,58]$. It has been also reported that Hes1, NOTCH1's downstream target protein, negatively regulates PTEN expression [51]. A fly model of tumorigenesis induced by NOTCH1 showed a synergism of NOTCH1 signaling and PI3K/AKT pathway, suggesting that the interplay between these two signaling pathways was conserved during the evolution process.

PRKAR1A has been found to be down-regulated in MCF-7 cells, due to the treatment with EFA-CLA. Information about PRKAR1A in available literature is ambiguous. Some studies have shown its up-regulation in many tumors, including breast cancer [7, 40, 41], suggesting its role in cell cycle regulation, growth, and/or proliferation. Other studies have pointed its tumor suppressing properties in osteosarcoma [49] and follicular thyroid cancer [55]. Due to EFA-CLA treatment, we determined a reduction in the mRNA expression of $U C P 2$, which belongs to the family of mitochondrial carriers. Significant amount of studies is available on $U C P 2$, but its functions are still under debate. It has been recently proposed to control routing of mitochondrial substrates $[20,69]$. The overexpression of UCP2 has been shown in various tumors, including breast cancer [44]. Some data reveal that up-regulation of UCP2 may facilitate an increased chemoresistance as well as cancer adaptation to oxidative stress via mitochondrial suppression of reactive oxygen species (ROS) $[4,15,18]$. Sayeed et al. [60] have shown that $U C P 2$ gene silencing rapidly led to the induction of apoptosis and differentiation in breast cancer cells, concurrent with reduced cell survival and proliferation. These results may be supported by numerous studies reporting evidences suggesting a correlation between oxidative stress and breast cancer, due to mitochondrial dysfunction [57]. Being the source of ROS, mitochondria are particularly exposed to potential oxidative DNA damage. Several studies have determined a higher rate of mitochondrial DNA (mtDNA) mutations in breast tumor tissue, specifically, they identified somatic mutations in the D-loop region as, probably, the major factor leading to decreased mtDNA level in breast tumors and indicating a poor prognosis [36]. Recent results have shown that a reduced number of mtDNA 
copy may be involved in cancer development and/or progression $[66,75]$ and mtDNA content might be potentially used as a tool to predict prognosis. Interestingly, in our unpublished studies on prostate cancer cells and melanoma, we determined a significant increase in the levels of mtDNA when treating with EFA-CLA extracts (compared to EFA).

We also determined a down-regulation of $H I G D 2 A$, a subunit of the cytochrome $\mathrm{C}$ oxidase (COX, complex IV). However, little is known about its mechanism of action. A study presented by An et al. [2] on HIGD1A, another member of HIG1 gene family, showed that expression of HIGD1A is directly dependent on binding of HIF- $1 \alpha$ to HRE (hypoxia-response element) site at $-32 \mathrm{bp}$ in the HIG1D1A promoter. Transfecting RAW264.7 cell line with HIGD1A under hypoxia condition promoted cell survival, whereas silencing the endogenous gene with siRNA resulted in hypoxia-induced apoptosis. The authors have proposed the inhibition of cytochrome $\mathrm{C}$ release and the reduction of caspases as a potential mechanism. They also obtained similar results for HIGD2A. It should be noted that similarity between $H I G 1$ gene family members might have influenced obtained microarray results as probe specificity for gene isoforms is limited [35]. Interestingly, in our unpublished results on prostate cancer cells and melanoma, we determined a down-regulation of HIF- $1 \alpha$, after treatment with EFA-CLA. In our present study, we also observed down-regulation of HIF-1 $\alpha$ in MCF-7 cells after EFA-CLA treatment, which is a positive signal confirming the anti-proliferative activity of EFA-CLA in the AKT/mTOR pathway (Fig. 5). HIF-1 $\alpha$ is responsible for the activation of transcription of various genes, such as $V E G F$, EDN1, or CDKN1A, which are involved in cell cycle regulation, neovascularization, and metastasis [62]. Overexpression of HIF- $1 \alpha$ correlates with an advanced tumor stage and poor survival $[63,68]$. Majumder et al. [43] have demonstrated that the expansion of AKT-driven prostate epithelial cells requires mTOR-dependent survival signaling and activation of HIF- $1 \alpha$.

Finally, our results showed a down-regulation of GNA12 mRNA expression after the treatment with EFACLA. Although we did not find a direct association with mTOR, GNA12 has been found to participate in oncogenesis and metastasis in pathological conditions [28]. Kim et al. [31]), while studying breast cancer cells, proposed that GNA12 up-regulates the activity of matrix metalloproteinase (MMP)-2 via p53-dependent manner and promotes malignant phenotypic conversion of this cancer cells. A recent study supported those findings [12]. Their results also show that GNA12 stimulates the expression and activity of tumor promoting cytokines IL- 6 and IL-8 and MMP-2 via binding and activation of NF-kB.

Although in current manuscript we focused on differences between the CLA-enriched (CLA-EFA) and non- enriched egg (EFAs), attached data (database GSE65397) suggest that EFAs can change the gene expression profile as well; however, they are unable to suppress the cell proliferation as efficiently as CLA-EFA can. The analysis of MCF-7 transcriptomes revealed that some of the observed changes may not be solely caused by CLA isomers present in the pool of other fatty acids identified in the enriched egg yolk. As shown in Fig. 1, the incorporation of CLA was accompanied by significant changes in the general FA profile of egg yolk. The most notable was an increase in total SFA concentration at the expense of MUFA. Our calculations showed that the altered SFA/ MUFA ratio can affect the expression of some genes including HIGD2A and SMS (Additional file 12: Table S11) suggesting that the changed FA ratio in EFA-CLA extract could be responsible, at least in part, for the specific response of the cancer cells (Fig 2). It seems therefore that our functional products, obtained through the process of modification of hens' diet, may show specific features determined by both the presence of CLA and altered SFA/MUFA ratio. This may also suggest that CLA-enriched eggs cannot be simply replaced with a synthetic CLA supplements.

Although available literature on effects of CLA on other FAs is limited, some authors have shown that treatment of cells with synthetic CLA increased the SFA/MUFA ratio in cell culture [14, 72]. As potential explanation, authors suggested that CLA could reduce the expression of SCD gene, which is responsible for conversion of SFA into MUFA. Interestingly, overexpression of SCD was associated with increased cancer cell proliferation, both in vitro for breast, prostate and lung cancer cells as well as in vivo $[5,14]$. Our results showed a decreasing tendency for SCD mRNA for EFA-CLA vs. EFA treatment groups (Table 1); however, these results were statistically non-significant. Nevertheless, comparison with the negative control revealed a significant reduction in SCD expression for EFA-CLA at the level of transcription (Additional file 7: Table S5). It should be noticed, however, that the SCD mRNA levels does not necessarily correspond with this enzyme activity that has been shown by Choi et al. [14] for both MDA-MB- 231 and MCF-7 cells treated with synthetic cis-9, trans-11 and trans-10, cis-12 CLA isomers. SCD has been also reported to be involved in mTOR pathway. Scaglia and Igal [61] have showed that the down-regulation of $S C D$ reduces the activity of AKT in A549 cell line (SCD-ablated A549 cells). In addition, Luyimbazi et al. [42] have observed an increase in SCD protein expression when using activators of mTOR pathway in both MCF-7 (ER+) and MDA-MB-231 (ER-) cell lines, while the use of selective mTOR inhibitors showed an opposite effect. All these data may suggest that the observed decrease in MCF-7 proliferation in the presence of EFA-CLA could 
result from down-regulation of $\mathrm{AKT} / \mathrm{mTOR}$ signaling pathway and reduced expression of SCD and other genes involved in mTOR pathway (database GSE65397). However, the role of CLA, other egg FAs, and the altered SFA/ MUFA ratio in mTOR-dependent down-regulation of cell proliferation needs further studies.

Although some of our results may require to be confirmed at protein levels, the microarrays are a valuable and multi-faceted source of information and may explain the adequacy of further in vivo research, according to $3 \mathrm{R}$ principles (replacement, reduction, and refinement).

\section{Conclusions}

In summary, our study presents the first evidence that the fatty acids extracts from CLA-enriched egg yolks (EFACLA) can affect transcriptome of MCF-7 cancer cells and inhibit their proliferation. We found this effect to be accompanied by changes in gene expression associated with down-regulation of AKT/mTOR signaling pathway. EFA-CLA increased expression of TSC2 and PTEN tumor suppressors as well as decreased the expression of oncogenes including NOTCH1, AGPS, GNA12, STAT3, UCP2, HIGD2A, HIF1A, and PPKAR1A. The observed results are most likely achieved by the combined effect of both incorporated CLA isomers and other fatty acids in eggs organically modified through hens' diet. It seems, therefore, that in contrast to synthetic CLA supplements, CLA-enriched eggs with an altered SFA/MUFA ratio could be easily available food products with a potential of a cancer chemopreventive agent. Although this concept needs further in vivo studies, it is clear that our microarray-derived results are a rich source of information on pathways in which fatty acids from CLA-enriched egg yolks can modify the response of the cancer cells at the level of transcription.

\section{Additional files}

Additional file 1: S1. Composition of hens' experimental diets (\%). (DOCX $12 \mathrm{~kb}$ )

Additional file 2: S2. FAME analysis GC/MS conditions. (DOCX $12 \mathrm{~kb}$ )

Additional file 3: S3. Nucleotide sequences of primers. ACTB, actin, beta; CAMSAP2, calmodulin regulated spectrin-associated protein family, member 2; GAPDH, glyceraldehyde-3-phosphate dehydrogenase; HIGD2A, HIG1 hypoxia inducible domain family, member 2A; HPRT1, hypoxanthine phosphoribosyltransferase 1; HSP9OAB1, heat shock protein $90 \mathrm{kDa}$ alpha (cytosolic); NAP1 1 1, nucleosome assembly protein 1-like 1; NOTCH1, Notch homolog 1, translocation-associated; PPKAR1A, protein kinase, CAMPdependent, regulatory, type I, alpha; PPP2R5E,protein phosphatase 2 , regulatory subunit $B^{\prime}$, epsilon isoform; TSC2, tuberous sclerosis 2; UCP2 uncoupling protein 2 (mitochondrial, proton carrier). (DOCX 14 kb)

Additional file 4: S12. Effect of EFA-CLA on MDA-MB-231 cells proliferation. The assay was performed using BrdU test (Roche). Values are expressed as means \pm SEM for the $N \geq 9$, standarized to $\mathrm{NC}$ as $100 \%$. Statistical significance was based on Student's $t$ test ${ }^{*} p<0.05$ vs. NC and $\wedge p<0.05$ vs. EFA. (TIF $40 \mathrm{~kb}$ )

Additional file 5: S4. Analysis of differently expressed transcripts between experimental groups in MCF-7 cell line. Tukey's HSD post hoc test $(p<0.05)$; underlining determined different transcripts between the compared groups; italics determined a common transcripts between the compared groups; bold determined all the analyzed transcripts. (DOCX $12 \mathrm{~kb}$ )

Additional file 6: S10. The list of the differently regulated EFA-CLA vs. EFA specific transcripts in MCF-7 cell line (without genes, which expression could directly be affected by the ET solvent). Statistical significance of treatment: $p<0.05$. (DOCX $30 \mathrm{~kb}$ )

Additional file 7: S5. The list of the differently regulated EFA vs. NC specific transcripts in MCF-7 cell line. ${ }^{*} p<0.05$ for EFA vs. NC; NC, negative control; NS $p>0.05$ (DOCX $17 \mathrm{~kb}$ )

Additional file 8: S6. Pathways based on EFA-CLA vs. EFA specific genes differently regulated in MCF-7 cell line. Statistical significance of treatment: $p<0.05$. (DOCX $14 \mathrm{~kb}$ )

Additional file 9: S7. Table GO biological processes based on EFA-CLA vs. EFA specific genes differently regulated in MCF-7 cell line. Statistical significance of treatment: $p<0.05$. (DOCX $13 \mathrm{~kb}$ )

Additional file 10: S8. GO molecular functions based on EFA-CLA vs. EFA specific genes differently regulated in MCF-7 cell line. Statistical significance of treatment: $p<0.05$. (DOCX $13 \mathrm{~kb}$ )

Additional file 11: S9. Protein classes based on EFA-CLA vs. EFA specific genes differently regulated in MCF-7 cell line. Statistical significance of treatment: $p<0.05$. (DOCX $13 \mathrm{~kb}$ )

Additional file 12: S11. Calculated effects of altered FA and SFA/MUFA (S/M) ratio on gene expression profile in MCF-7 cells. ${ }^{*}$ potential role of SFA/MUFA ratio in the regulation of gene expression. Abbreviations: $c 9$. t11CLA-cis-9.trans-11-CLA; t10. c12CLA-trans-10.cis-12-CLA. S/M. changed SFA/MUFA ratio. (DOCX $18 \mathrm{~kb}$ )

\section{Abbreviations}

AKT, protein kinase B; BF3, boron trifulouride; BHT, butylated hydroxytoluen; BrdU, 5'-bromo-2'-deoxy-uridine; CLA, conjugated linoleic acid; COX, cytochrome C oxidase; DNA, deoxyribonucleic acid; EC, empty control; EFA, fatty acids extract from non-enriched egg yolks; EFA-CLA, fatty acids extract from CLA-enriched egg yolks; FA, fatty acids; FAME, fatty acid methyl esters; FC, fold change; GC/MS, gas chrmoatography/mass spectrometry; GO, Gene Ontology; HRE, hypoxia-response element; $\mathrm{KOH}$, potassium hydroxide; MCF-7, human breast adenocarcinoma cell line; mtDNA, mitochondrial DNA; mTOR, mammalian target of rapamycin; NC, negative control; QC, quality control; RNA, ribonucleic acid; ROS, reactive oxygen species; siRNA, small interfering RNA

\section{Funding}

This work was supported by the Polish National Science Center (grant number 2011/03/B/NZ9/01423) "Conjugated linoleic acid (CLA)-induced transcriptional activation of PPAR-an investigation of molecular mechanisms of putative anticancer action of fatty acids of CLA-enriched egg yolks."

\section{Availability of data and materials}

Microarray data were deposited at the Gene Expression Omnibus data repository under the number GSE65397.

\section{Authors' contributions}

AAK, AM, and PL made substantial contributions to the conception and design of experiments. DD, EP, MM, and AAK participated in performing the experiments. AAK and AM participated in the analysis and interpretation of data. AAK and PB participated in drafting the article. PL and AM participated in critically revising article for its important intellectual content. TL gave the final approval of the version to be submitted and any revised version. All authors read and approved the final manuscript.

\section{Competing interests}

The authors declare that they have no competing interests.

\section{Ethics approval and consent to participate}

The Animal Ethics Committee of the National Institute of Animal Production (Poland) approved all experiments involving animals (approval number: 851/ 2011). All applicable international, national, and/or institutional guidelines for the care and use of animals were followed. 


\section{Author details}

'Department of Human Nutrition, Faculty of Food Technology, University of Agriculture, Krakow, Poland. ${ }^{2}$ Department of Biochemistry and Molecular Biology, Medical Centre for Postgraduate Education, Warsaw, Poland. ${ }^{3}$ Department of Medical Biochemistry, Jagiellonian University Medical College, Krakow, Poland.

\section{Received: 4 May 2016 Accepted: 12 July 2016}

\section{Published online: 27 July 2016}

\section{Reference}

1. Albers R, Van der Wielen RPJ, Brink EJ, Hendrix HF, Dorovska-Taran VN, Mohede IC. Effects of cis-9, trans-11 and trans-10, cis-12 conjugated linoleic acid (CLA) isomers on immune function in healthy men. Eur J Clin Nutr. 2003:57(4):595-603.

2. An HJ, Shin H, Jo SG, Kim YJ, Lee JO, Paik SG, et al. The survival effect of mitochondrial Higd-1a is associated with suppression of cytochrome $\mathrm{C}$ release and prevention of caspase activation. Biochim Biophys Acta. 2011;1813(12):2088-98.

3. AOAC. Official methods of analysis. 18th ed. Gaintersburg: Association of Offcial Analitical Chemists International; 2006.

4. Baffy G, Derdak Z, Robson SC. Mitochondrial recoupling: a novel therapeutic strategy for cancer? Br J Cancer. 2011;105(4):469-74.

5. Belkaid A, Duquay SR, Ouellette RJ, Surette ME. 17ß-estradiol induces stearoyl-CoA desaturase-1 expression in estrogen receptor-positive breast cancer cells. BMC Cancer. 2015:29(15):440.

6. Benjamin DI, Cozzo A, Ji X, Roberts LS, Louie SM, Mulvihill MM, et al. Ether lipid generating enzyme AGPS alters the balance of structural and signaling lipids to fuel cancer pathogenicity. Proc Natl Acad Sci U S A. 2013;110(37):14912-7.

7. Beristain AG, Molyneux SD, Joshi PA, Pomroy NC, Di Grappa MA, Chang M, et al. PKA signaling drives mammary tumorigenesis through Src. Oncogene. 2015;34(9):1160-73.

8. Boulay A, Rudloff J, Ye J, Zumstein-Macker S, O'Reilly T, Evans DB, Chen S, Lane HA. Dual inhibition of mTOR and estrogen receptor signaling in vitro induces cell death in models of breast cancer. Clin Cancer Res. 2005;11(14):5319-28.

9. Bose S, Crane A, Hibshoosh H, Mansukhani M, Sandweis L, Parsons R. Reduced expression of PTEN correlates with breast cancer progression. Hum Pathol. 2002;33(4):405-9.

10. Calzavara E, Chiaramonte R, Cesana D, Basile A, Sherbet GV, Comi P. Reciprocal regulation of Notch and PI3K/Akt signalling in T-ALL cells in vitro. J Cell Biochem. 2008;103(5):1405-12.

11. Chamruspollert M, Sell JL. Transfer of dietary conjugated linoleic acid to egg yolks of chickens. Poult Sci. 1999;78(8):1138-50.

12. Chia CY, Kumari U, Casey PJ. Breast cancer cell invasion mediated by Ga12 signaling involves expression of interleukins- 6 and -8 , and matrix metalloproteinase-2. J Mol Signal. 2014;9:6.

13. Chin SF, Liu W, Storkson JM, Ha YL, Pariza MW. Dietary sources of conjugated dienoic isomers of linoleic acid, a newly recognized class of anticarcinogens. J Food Comp Anal. 1992;5(3):185-97.

14. Choi Y, Park Y, Storkson JM, Pariza MW, Ntambi JM. Inhibition of stearoylCoA desaturase activity by the cis-9, trans-11 isomer and the trans-10, cis-12 isomer of conjugated linoleic acid in MDA-MB- 231 and MCF-7 human breast cancer cells. Biochem Biophys Res Commun. 2002;294(4):785-90.

15. Dalla Pozza E, Fiorini C, Dando I, Menegazzi M, Sgarbossa A, Constanzo C, et al. Role of mitochondrial uncoupling protein 2 in cancer cell resistance to gemcitabine. Biochim Biophys Acta. 2012;1823(10):1856-63.

16. De la Torre A, Debiton E, Juanéda P, Durand D, Chardigny J-M, Barthomeuf $C$, et al. Beef conjugated linoleic acid isomers reduce human cancer cell growth even when associated with other beef fatty acids. Br J Nutr. 2006;95(2):346-52.

17. Deocampo ND, Huang $H$, Tindall DJ. The role of PTEN in the progression and survival of prostate cancer. Minerva Endocrinol. 2003;28(2):145-53.

18. Derdak Z, Mark NM, Beldi G, Robson SC, Wands JR, Baffy G. The mitochondrial uncoupling protein-2 promotes chemoresistance in cancer cells. Cancer Res. 2008;68(8):2813-9.

19. Dupont WD, Breyer JP, Bradley KM, Schuyler PA, Plummer WD, Sanders ME, et al. Protein phosphatase 2A subunit gene haplotypes and proliferative breast disease modify breast cancer risk. Cancer. 2010;116(1):8-19.

20. Esteves $P$, Pecqueur C, Ransy C, Esnous C, Lenoir V, Bouillaud F, et al. Mitochondrial retrograde signaling mediated by UCP2 inhibits cancer cell proliferation and tumorigenesis. Cancer Res. 2014;74(14):3971-82.
21. Ferlay J, Soerjomataram I, Ervik M, Dikshit R, Eser S, Mathers C, Rebelo M, Parkin DM, Forman D, Bray F, GLOBOCAN 2012 v1.0, Cancer incidence and morality worldwide: IARC Cancer Base No. 11 [Internet]. Lyon, France: International Agency for Research on Cancer; 2013. Available from: http:// globocan.iarc.fr/. Accessed 16 Jan 2015.

22. Folch J, Lees $M$, Sloane-Stanley $\mathrm{GH}$. A simple method for the isolation and purification of total lipids from animal tissues. J Biol Chem. 1957;226(1):497-509.

23. Fortuna T, Juszczak L, Sobolewska-Zielińska J. Basis for food analysis. A script for laboratory classes at the University of Agriculture in Krakow. Krakow: Publishing House of the University of Agriculture in Krakow; 2003.

24. Franczyk-Żarów M, Kostogrys RB, Szymczyk B, Jawień J, Gajda M, Cichocki T, et al. Functional effects of eggs, naturally enriched with conjugated linoleic acid, on the blood lipid profile, development of atherosclerosis and composition of atherosclerotic plaque in apolipoprotein $\mathrm{E}$ and low-density lipoprotein receptor double-knockout mice (apoE/LDLR-/-). Br J Nutr. 2008;99(1):49-58.

25. Griinari JM, Bauman DE. Biosynthesis of conjugated linoleic acid and its incorporation into meat and milk in ruminants. In: Yurawecz MP, Mossoba MM, Kramer JKG, Pariza MW, Nelson GJ, editors. Advances in conjugated linoleic acid research, vol. 1. Champaign, IL: AOSC Press; 1999. p. 180-200

26. Holliday DL, Speirs V. Choosing the right cell line for breast cancer research. Breast Cancer Res. 2011:13(4):215. doi:10.1186/bcr2889.

27. Ip C, Scimeca JA, Thompson HJ. Conjugated linoleic acid. A powerful anticarcinogen from animal fat sources. Cancer. 1994;74(3 Suppl):1050-4.

28. Juneja J, Casey PJ. Role of G12 proteins in oncogenesis and metastasis. Br J Pharmacol. 2009:158(1):32-40.

29. Kang YJ, Lu MK, Guan KL. The TSC1 and TSC2 tumor suppressors are required for proper ER stress response and protect cells from ER stress-induced apoptosis. Cell Death Differ. 2011;18(1):133-44.

30. Kepler CR, Hirons KP, McNeill JJ, Tove SB. Intermediates and products of the biohydrogenation of linoleic acid by Butyrivibrio fibrisolvens. J Biol Chem. 1966:241:1350-4.

31. Kim ES, Jeong JB, Kim S, Lee KM, Ko E, Noh DY, et al. The G12 family proteins upregulate matrix metalloproteinase-2 via p53 leading to human breast cell invasion. Breast Cancer Res Treat. 2010;124(1):49-61.

32. Koronowicz A, Dulińska-Litewka J, Pisulewski P, Laidler P. Effect of conjugated linoleic acid isomers on proliferation of mammary cancer cells. Rocz Panstw Zakl Hig. 2009;60(3):261-7.

33. Koronowicz A, Banks P, Szymczyk B, Leszczyńska T, Master A, Piasna E, Szczepański W, Domagała D, Kopeć A, Piątkowska E \& Laidler P (2016): Dietary conjugated linoleic acid affects blood parameters, liver morphology and expression of selected hepatic genes in laying hens, British Poultry Science, DOl:10.1080/00071668.2016.1192280.

34. Kostogrys RB, Franczyk-Żarów M, Maślak E, Gajda M, Mateuszuk Ł, Chłopicki S. Effects of margarine supplemented with T10C12 and C9T11 CLA on atherosclerosis and steatosis in apoE/LDLR-/-mice. J Nutr Health Aging. 2012:16(5):482-90.

35. Kothapalli R, Yoder SJ, Mane $\mathrm{S}$, et al. Microarray results: how accurate are they? BMC Bioinformatics. 2002:3:22.

36. Kuo SJ, Chen M, Ma GC, Chen ST, Chang SP, Lin WY, et al. Number of somatic mutations in the mitochondrial D-loop region indicates poor prognosis in breast cancer, independent of TP53 mutation. Cancer Genet Cytogenet. 2010:201(2):94-101.

37. Laplante M, Sabatini DM. mTOR signaling in growth control and disease. Cell. 2012;149(2):274-93.

38. Liu X, Liu Q, Fan Y, Wang S, Liu X, Zhu L, et al. Downregulation of PPP2R5E expression by miR-23a suppresses apoptosis to facilitate the growth of gastric cancer cells. FEBS Lett. 2014;588(17):3160-9.

39. Livak KJ, Schmittgen TD. Analysis of relative gene expression data using real-time quantitative PCR and the 2 (-delta delta $C(T)$ ) method. Methods. 2001:25(4):402-8.

40. Loilome W, Juntana S, Namwat N, Bhudhisawasdi V, Puapairoj A, Sripa B, et al. PRKAR1A is overexpressed and represents a possible therapeutic target in human cholangiocarcinoma. Int J Cancer. 2011:129(1):34-44.

41. Loilome W, Juntana S, Pinitsoontorn C, Namwat N, Tassaneeyakul W, Yongvanit P. Suppression of PRKAR1A expression enhances antiproliferative and apoptotic effects of protein kinase inhibitors and chemotherapeutic drugs on cholangiocarcinoma cells. Asian Pac Cancer Prev. 2012;13(Suppl):143-7. 
42. Luyimbazi D, Akcakanat A, McAuliffe PF, Zhang L, Singh G, Gonzalez-Angulo AM, Chen H, Do K-A, Zheng Y, Hung M-C, Mills GB, Meric-Bernstam F. Rapamycin regulates stearoyl CoA desaturase 1 expression in breast cancer. Mol Cancer Ther. 2010;9(10):2770-84.

43. Majumder PK, Febbo PG, Bikoff R, Berger R, Xue Q, McMahon LM, et al (2004) mTOR inhibition reverses Akt-dependent prostate intraepithelial neoplasia through regulation of apoptotic and HIF-1-dependent pathways. Nat Med. 2004;10(6):594-601.

44. Maraghechi N, Ghaffarpour M, Tehrani GA. Overexpression of UCP2 is associated with tumor progression in Iranian breast cancer patients. Cancer Res. 2014;74(19 Supplement):4325.

45. Mehta MS, Vazquez A, Kulkarni DA, Kerrigan JE, Atwal G, Metsugi S, et al. Polymorphic variants in TSC1 and TSC2 and their association with breast cancer phenotypes. Breast Cancer Res Treat. 2011;125(3):861-8.

46. Miller A, Stanton C, Murphy J, Devery R. Conjugated linoleic acid (CLA)enriched milk fat inhibits growth and modulates CLA-responsive biomarkers in MCF-7 and SW480 human cancer cell lines. Br J Nutr. 2003;90(5):877-85.

47. Mir PS, McAllister TA, Scott S, Alhaus J, Baron V, McCartney D, et al. Conjugated linoleic acid-enriched beef production. Am J Clin Nutr. 2004; 79(6 Suppl):1207S-11S.

48. Mitra S, Khaidakov M, Lu J, Ayyadevara S, Szwedo J, Wang XW, et al. Prior exposure to oxidized low-density lipoprotein limits apoptosis in subsequent generations of endothelial cells by altering promoter methylation. Am J Physiol Heart Circ Physiol. 2011;301(2):H506-13.

49. Molyneux SD, Di Grappa MA, Beristain AG, McKee TD, Wai DH, Pederova J, et al. Prkar1a is an osteosarcoma tumor suppressor that defines a molecular subclass in mice. J Clin Invest. 2010;120(9):3310.

50. Murphy EF, Hooiveld GJ, Muller M, Calogero RA, Cashman KD. Conjugated linoleic acid alters global gene expression in human intestinal-like Caco-2 cells in an isomer-specific manner. J Nutr. 2007;137(11):2359-65.

51. Palomero T, Sulis ML, Cortina M, Real PJ, Barnes K, Ciofani M, et al. Mutational loss of PTEN induces resistance to NOTCH1 inhibition in T-cell leukemia. Nat Med. 2007;13(10):1203-10.

52. Pariza MW, Ha YL. Conjugated dienoic derivatives of linoleic acid: a new class of anticarcinogens. Med Oncol Tumor Pharmacother. 1990;7(2-3):169-71.

53. Park S-B, Kim B, Bae H, Lee H, Lee S, Choi EH, et al. Differential epigenetic effects of atmospheric cold plasma on MCF-7 and MDA-MB-231 breast cancer cells. PLoS ONE. 2015;10(6):e0129931. doi:10.1371/journal.pone.0129931.

54. Park Y, Albright KJ, Liu W, Storkson JM, Cook ME, Pariza MW. Effect of conjugated linoleic acid on body composition in mice. Lipids. 1997;32(8):853-8.

55. Pringle DR, Vasko W, Yu L, Manchanda PK, Lee AA, Zhang X. Follicular thyroid cancers demonstrate dual activation of PKA and MTOR as modeled by thyroid-specific deletion of Prkar1a and Pten in mice. J Clin Endocrinol Metab. 2014;99(5):E804-12.

56. Qu Y, Han B, Yu Y, Yao W, Bose S, Karlan BY, et al. Evaluation of MCF10A as a reliable model for normal human mammary epithelial cells. PLoS ONE. 2015;10(7):e0131285. doi:10.1371/journal.pone.0131285.

57. Rohan TE, Wong LJ, Wang T, Haines J, Kabat GC (2010) Do alterations in mitochondrial DNA play a role in breast carcinogenesis? J Oncol 11 pages. doi:10.1155/2010/604304

58. Sade $H$, Krishna S, Sarin A. The anti-apoptotic effect of Notch-1 requires p56lck-dependent, Akt/PKB-mediated signaling in T cells. J Biol Chem. 2004;279(4):2937-44.

59. Savanur MA, Eligar SM, Pujari R, Chen C, Mahajan P, Borges A, et al. Sclerotium rolfsii lectin induces stronger inhibition of proliferation in human breast cancer cells than normal human mammary epithelial cells by induction of cell apoptosis. PLoS ONE. 2014;9(11):e110107. doi:10.1371/journal.pone.0110107.

60. Sayeed A, Meng Z, Luciani G, Chen L-C, Bennington JL, Dairkee SH. Negative regulation of UCP2 by TGF 3 signaling characterizes low and intermediate-grade primary breast cancer. Cell Death Dis. 2010;1(7):e53.

61. Scaglia N, Igal RA. Inhibition of stearoyl-CoA desaturase 1 expression in human lung adenocarcinoma cells impairs tumorigenesis. Int J Oncol. 2008;33(4):839-50

62. Semenza GL. Signal transduction to hypoxia-inducible factor 1. Biochem Pharmacol. 2002;64(5-6):993-8.

63. Shibaji T, Nagao M, Ikeda N, Kanehiro H, Hisanaga M, Ko S, et al. Prognostic significance of HIF-1 alpha overexpression in human pancreatic cancer. Anticancer Res. 2003:23(60):4721-7.
64. Song MS, Salmena L, Pandolfi PP. The functions and regulation of the PTEN tumor suppressor. Nat Rev Mol Cell Biol. 2012;13(5):283-96.

65. Szymczyk B, Pisulewski PM. Effects of dietary conjugated linoleic acid on fatty acid composition and cholesterol content of hen egg yolks. Br J Nutr. 2003;90(1):93-9.

66. Thyagarajan B, Wang R, Nelson H, Barcelo H, Koh WP, Yuan JM. Mitochondrial DNA copy number is associated with breast cancer risk. PLoS One. 2013;8(6):e65968.

67. Törnqvist E, Annas A, Granath B, Jalkesten E, Cotgreave I, Öberg M. Strategic focus on $3 R$ principles reveals major reductions in the use of animals in pharmaceutical toxicity testing. PLoS One. 2014;9(7):e101638. doi:10.1371/journal.pone.0101638.

68. Vaupel P. The role of hypoxia-induced factors in tumor progression. Oncologist. 2004;9 Suppl 5:10-7.

69. Vozza A, Parisi G, De Leonardis F, Lasorsa FM, Castegna A, Amorese D, et al. UCP2 transports C4 metabolites out of mitochondria, regulating glucose and glutamine oxidation. Proc Natl Acad Sci U S A. 2014;111(3):960-5.

70. Wang Q, Wang X, Evers BM. Induction of CIAP-2 in human colon cancer cells through PKC8/NF-kB. J Biol Chem. 2003;278(51):51091-9.

71. Xue G, Hao LQ, Ding FX, Mei Q, Huang JJ, Fu CG, et al. Expression of annexin 25 is associated with higher tumor stage and poor prognosis in colorectal adenocarcinomas. J Clin Gastroenterol. 2009:43(9):831-7.

72. Yamasaki M, Yanagita T. Adipocyte response to conjugated linoleic acid. Obes Res Clin Pract. 2013;7(4):e235-42.

73. Yao P-L, Morales JL, Zhu B, Kang B-H, Gonzalez FJ, Peters JM. Activation of peroxisome proliferator-activated receptor- $\beta / \delta($ PPAR $/ \delta)$ inhibits human breast cancer cell line tumorigenicity. Mol Cancer Ther. 2014;13(4):1008-17.

74. Yin JD, Shang XG, Li DF, Wang FL, Guan YF, Wang ZY. Effects of dietary conjugated linoleic acid on the fatty acid profile and cholesterol content of egg yolks from different breeds of layers. Poult Sci. 2008;87(2):284-90.

75. Yu M, Zhou Y, Shi Y, Ning L, Yang $Y$, Wei $X$, et al. Reduced mitochondrial DNA copy number is correlated with tumor progression and prognosis in Chinese breast cancer patients. IUBMB Life. 2007:59(7):450-7.

76. Yusuf R, Frenkel K. Morphologic transformation of human breast epithelial cells MCF-10A: dependence on an oxidative microenvironment and estrogen/epidermal growth factor receptors. Cancer Cell Int. 2010;10:30. doi:10.1186/1475-2867-10-30

77. Zhu Y, Liu A, Zhang X, Qi L, Zhang L, Xue J, et al. The effect of benzyl isothiocyanate and its computer-aided design derivants targeting alkylglycerone phosphate synthase on the inhibition of human glioma U87MG cell line. Tumor Biol. 2015;36(5):3499-509.

78. Zlatanos SN, Laskaridis K, Sagredos A. Conjugated linoleic acid content of human plasma. Lipids Health Dis. 2008;7:34.

79. PI3K-Akt signaling pathway. http://www.genome.jp/dbget-bin/www_ bget?map04151. Accessed 28 April 2016.

\section{Submit your next manuscript to BioMed Central and we will help you at every step:}

- We accept pre-submission inquiries

- Our selector tool helps you to find the most relevant journal

- We provide round the clock customer support

- Convenient online submission

- Thorough peer review

- Inclusion in PubMed and all major indexing services

- Maximum visibility for your research

Submit your manuscript at www.biomedcentral.com/submit 